\title{
LA PERSECUCIÓN RELIGIOSA EN ESPAÑA (1931-1939); UNA APORTACIÓN SOBRE LAS CIFRAS
}

\author{
POR
}

\author{
Angel David Martín Rubio \\ Seminario Diocesano - Cáceres
}

\begin{abstract}
RESUMEN
El autor considera que todavía no se ha realizado una síntesis válida para comprender la distintia clasificación de los religiosos víctimas de la Guerra Civil, incluyendo la revolución de Asturias en 1934. Elabora una base de datos clasificando las víctimas por zonas y categorías.
\end{abstract}

PALABRAS ClAVE: Víctimas religiosas. Guerra Civil Española. Asturias.

\begin{abstract}
The author thinks that still hasn't been realized a valid synthesis in order to understand the different classification of the religious who were victims of Spanish Civil War, what includes the revolution of Asturias in 1934. He makes his own data base in which he classifies the victims according to areas and qualities.
\end{abstract}

KEY WORDS: Religious victims. Spanish Civil War. Asturias.

Esta comunicación responde a la necesidad de elaborar una síntesis acerca de los efectos reales de la persecución religiosa desencadenada en España durante la Segunda República (1931-1939) que responda a cuestiones como la elaboración de un catálogo actualizado de las víctimas eclesiásticas y la realización de un estudio preciso sobre su reparto geográfico y cronológico.

A partir de una base de datos en la que aparecen todos los sacerdotes, religiosos, religiosas y seminaristas víctimas de la persecución, hemos obtenido un nuevo listado que, sin duda, tendrá errores y omisiones pero que, hoy por hoy, es lo más completo posible. En espera de poder dar cifras definitivas hacemos aquí

Actas del I Congreso de Historia de la Iglesia y el Mundo Hispánico Hispania Sacra 53 (2001) 
una primera estimación bastante fiable en lo que se refiere al resto de las cuestiones aludidas.

Después de referirnos al prólogo que supuso la Revolución de Asturias (con 37 asesinatos de sacerdotes, religiosos y seminaristas) nos detenemos en el reparto regional llegando a la conclusión de que los mayores porcentajes se alcanzaron en Cataluña, Levante y la franja central mientras que el norte y el sur resultaron, proporcionalmente, menos castigados.

Especialmente relevante resulta la relación entre persecución religiosa y represión de carácter sociopolítico ya que se da una coincidencia total en el tiempo y el espacio. Las víctimas eclesiásticas fueron más numerosas, lógicamente, en aquellas zonas donde la represión en general fue más dura aunque puede decirse que la persecución religiosa se dio en la totalidad del territorio sometido a la represión republicana.

Por lo que se refiere a la cronología, la fecha en que se sitúa el máximo de víctimas oscila, según las zonas, entre los diversos meses del verano y el otoño de 1936 pero en la mayoría de las provincias fue agosto la que concentra las cifras más elevadas.

En último lugar hacemos algunas consideraciones, necesariamente breves, acerca de los incendios, saqueos y profanaciones de lugares sagrados y objetos de culto. Se trata de hechos especialmente significativos pues ponen de relieve la especificidad antirreligiosa de la persecución y cómo a través de la destrucción de los elementos simbólicos más representativos se manifestaba el intento de desarticular el orden anterior y de implantar uno nuevo.

En un artículo publicado recientemente en Hispania Sacra ${ }^{1}$ hacíamos ver la necesidad de elaborar una nueva síntesis acerca de la persecución religiosa desencadenada en España entre 1931 y 1939 que permitiera establecer, como punto de partida para una investigación de más amplio alcance, los siguientes elementos:

- Un catálogo actualizado de las víctimas eclesiásticas².

- Un estudio preciso sobre el reparto geográfico de los asesinatos. Como hemos afirmado en otras ocasiones, los datos que se han proporcionado a través de las diócesis son incompletos por referirse únicamente al clero secular y por la dificultad en hacer coincidir los límites provinciales con los

1 Ángel David MARTiN RUBIO, La persecución religiosa de 1936-1939: Estado de la cuestión y propuestas historiográficas, en Hispania Sacra 49 (1997), pp. 43-71.

2 Hasta ahora, sólo disponemos de dos: el que apareció en Guía de la Iglesia en España, Oficina General de Información y Estadística de la Iglesia en España, Madrid, 1954, 207-279 y el que elaboró Antonio MONTERO MORENO y que aparece en su Historia de la persecución religiosa en España, 1936-1939, BAC, Madrid, 1961; 769-883. Ambos estaban necesitados de profunda revisión. 
cular y por la dificultad en hacer coincidir los límites provinciales con los diocesanos.

- El porcentaje que suponen las muertes de eclesiásticos sobre el total de víctimas de la represión republicana.

- El reparto cronológico3.

- Impacto real de las diversas manifestaciones de la persecución religiosa:

1. Asesinatos de obispos, sacerdotes, religiosos, monjas y seminaristas.

2. Asesinatos de seglares por motivos religiosos.

3. Detenciones y encarcelamientos de eclesiásticos y seglares.

4. Organización clandestina de la caridad y el culto.

5. Incendios, saqueos y profanaciones.

Para dar una respuesta a todos estos interrogantes, anunciábamos nuestra intención de llevar a cabo un trabajo de investigación a partir de la aplicación de una metodología que nos permite conclusiones a nivel regional y, desde ahí, para toda la parte del territorio nacional que sufrió la persecución religiosa.

El largo proceso del que adelantamos ahora unas primeras conclusiones está consistiendo, entre otros, en los siguientes pasos:

- Elaboración de una base de datos en la que aparecen todos los sacerdotes, religiosos, religiosas y seminaristas víctimas de la persecución religiosa entre 1934 y 1939. Para llevar a cabo este listado hemos tomado como punto de partida el que aparece en la obra de A. Montero Moreno y lo hemos corregido y completado con los datos publicados en las monografías posteriores a 1961 y con el resultado de nuestra propia investigación en el Archivo Histórico Nacional (Sección Guerra Civil:Causa General) y en numerosos Registros Civiles. El proceso ha sido lento porque ha sido necesario corregir errores, eliminar nombres que aparecían duplicados, añadir datos ...

El resultado es un nuevo catálogo que, sin duda, tendrá errores y omisiones pero que, hoy por hoy, es lo más completo posible. Nos queda aún por revisar algunas fichas para establecer las cifras definitivas pero las ya obtenidas nos permiten una aproximación muy fiable y prácticamente definitiva en lo que se refiere al resto de las cuestiones (reparto regional, cronología...)

- A continuación se han distribuido las víctimas por provincias siguiendo como criterio el lugar de muerte. En algunos casos ignoramos este último

3 Jesús SALAS LARRAZÁBAL, publicó una aproximación a partir de los datos de Montero: en $L a$ guerra de España desde el aire, Ariel, Barcelona, 1972, pp. 489-491.

Actas del I Congreso de Historia de la Iglesia y el Mundo Hispánico Hispania Sacra 53 (2001) 
dato pero como es previsible que, en la mayoría de estos casos, coincidiera lugar de residencia y lugar de muerte - al menos dentro de los mismos límites provinciales - únicamente nos han quedado sin asignarles una provincia un 5\% de los casos. En todo caso, este porcentaje tan reducido no invalidará las conclusiones globales a nivel provincial ni, mucho menos, regional o nacional.

- Con este material, se ha procedido al análisis de lo que ocurrió en cada provincia. En concreto nos interesaban las cuestiones aludidas:

- Total de víctimas.

- Distribución entre clero secular, religiosos, religiosas y seminaristas.

- Cronología.

- Relación con la represión republicana ${ }^{4}$.

- Por último, a partir de estos datos, será posible una visión de conjunto acerca de los efectos reales de la persecución religiosa en España.

Damos, por lo tanto, en este artículo un avance de los resultados obtenidos a la espera de poder perfilarlos definitivamente en una publicación posterior, una vez que logremos concretar ese aproximadamente $5 \%$ del total de víctimas para el que debemos concretar algunos datos.

\section{UN PRÓLOGO: 1931-1936}

Todas las muertes de eclesiásticos ocurridas con anterioridad a 1936, tuvieron lugar con ocasión de la Revolución de Octubre de 1934.

Ofrecemos a continuación un balance de los asesinatos de eclesiásticos que, en el caso de Asturias, representan en torno al 56\% de los civiles muertos con ocasión de la violencia revolucionaria desencadenada en estos sucesos ${ }^{5}$.

4 Poner en relación persecución religiosa y represión republicana nos ha sido posible gracias a la elaboración previa de un trabajo en el que se daba respuesta a esta segunda cuestión: cfr. Ángel David MARTIN RUBIO, Paz, piedad, perdón...y verdad, Fénix, Madrid, 1997.

5 Cfr., Enrique BARCO TERUEL, El golpe socialista (octubre 1934), Dyrsa, Madrid, 1984, 248250; Joaquín ARRARÁs (dir.), Historia de la Cruzada Española, II, Publicaciones españolas, Madrid, 1940; A.C.N. de Propagandistas de Oviedo, Asturias roja. Sacerdotes y religiosos perseguidos y asesinados (octubre 1934), Imprenta Trufero, Oviedo, 1935. El porcentaje de la persecución religiosa sobre el total de víctimas no es preciso pues desconocemos el número exacto de guardias civiles asesinados en Pola de Lena, Sama de Langreo y Santa Cruz y de guardias de asalto en Mieres.

Actas del I Congreso de Historia de la Iglesia y el Mundo Hispánico

Hispania Sacra 53 (2001) 


\begin{tabular}{ccc}
\hline GRUPO & & VíCTIMAS \\
\hline Religiosos & Carmelita Descalzo & 1 \\
& Hermanos de La Salle & 8 \\
& Jesuitas & 2 \\
& Marista & 1 \\
& Pasionistas & 3 \\
Total Religiosos & Paúles & 3 \\
Sacerdotes & Cabildo Catedral & $\mathbf{1 8}$ \\
& Curia & 1 \\
& Ecónomos & 2 \\
Total Sacerdotes & Párrocos & 1 \\
Total Seminaristas & Regentes & 7 \\
\hline TotaL & & 1 \\
\hline
\end{tabular}

La cronología es la siguiente:

\begin{tabular}{ccc}
\hline FECHA & VíCTIMAS & PORCENTAJE \\
\hline 5-oct-34 & 6 (2 sacerdotes y 2 pasionistas) & 16.22 \\
6-oct-34 & 2 (1 marista y 1 sacerdote) & 5.41 \\
7-oct-34 & 9 (1 sacerdote, 1 paúl, 7 seminaristas & 24.32 \\
8-oct-34 & 4 (2 sacerdotes y 2 jesuitas) & 10.81 \\
9-oct-34 & 10 (8 hermanos de la Salle, & 27.03 \\
& 1 pasionista y 1 sacerdote) \\
10-oct-34 & 2 (sacerdotes) & 5.41 \\
11-oct-34 & 1 (sacerdote) & 2.7 \\
12-oct-34 & 1 (carmelita) & 2.7 \\
13-oct-34 & 2 (paúles) \\
\hline TOTAL & 37 \\
\hline
\end{tabular}


Estas muertes tuvieron lugar en diversas localidades de Asturias aunque también hubo algunos casos en Cantabria, Lérida y Palencia:

\begin{tabular}{ccc}
\hline PROVINCIA & LUGAR DE MUERTE & VÍCTIMAS \\
\hline Asturias & Mieres & 3 \\
& Moreda & 1 \\
& Olloniego & 1 \\
& Oviedo & 15 \\
& Sama de Langreo & 1 \\
& Santullano & 2 \\
& Turón & 9 \\
& Valdecuna & 1 \\
Total Asturias & Laredo & 33 \\
Cantabria & Navas & 1 \\
Lérida & Barruelo & 1 \\
Palencia & Muñecas & 1 \\
Total Palencia & & 1 \\
\hline ToTAL & & $\mathbf{3 7}$ \\
\hline
\end{tabular}

Aunque la violencia se cobró numerosas víctimas en los momentos previos a la guerra ${ }^{6}$, solo hemos encontrado referencia precisa a la muerte de un seminarista:

«El Martirologio vicense anota como primera víctima un precursor, antes del Alzamiento, seminarista teólogo. Terminado el curso, se dirigía a su casa de vacaciones, aún de sotana. José Moncosí Castells fue traicioneramente asesinado por unos revolucionarios que fingieron darle protección y dispararon a su espalda, por la carretera de San Juan de las Abadesas»?

\section{LAS CIFRAS Y SU REPARTO GEOGRÁFICO.}

Con todas las salvedades que hemos apuntado, podemos atribuir, provisionalmente y como punto de partida, a la persecución religiosa el siguiente número de bajas:

6 Cfr., Stanley PAYNE, La primera democracia española, Paidós, Barcelona, 1995, pp. 319-327, $344-347$ y 378 ss.

7 Fernando GÓMEz CATÓN, La Iglesia de los mártires en la provincia eclesiástica tarraconense, II, Mare nostrum, Barcelona, 1989, p. 39.

Actas del I Congreso de Historia de la Iglesia y el Mundo Hispánico Hispania Sacra 53 (2001) 


\begin{tabular}{ccc}
\hline GRUPO & VÍCTIMAS & PORCENTAJE \\
\hline Administrador apostólico & 1 & \\
Obispos & 12 & 0.19 \\
Religiosas & 288 & 4.25 \\
Religiosos & 2373 & 35.05 \\
Sacerdotes & 4011 & 59.24 \\
Seminaristas & 86 & 1.27 \\
\hline TOTAL & $\mathbf{6 7 7 1}$ & $\mathbf{1 0 0}$ \\
\hline
\end{tabular}

Contra lo que se podía esperar no hay un aumento considerable de las cifras propuestas en $1961^{8}$ pues, aunque de los estudios de algunas diócesis se deducía una corrección al alza, al haber suprimido numerosas repeticiones que aparecen en el listado de Montero Moreno, los valores acaban equiparándose. Tampoco debe sorprender que no hayan aparecido demasiados nombres nuevos porque parece lógico que cada congregación o diócesis identificara a la práctica totalidad de sus bajas en los listados parciales de que ya disponíamos pero lo realmente difícil era dar una cifra global pues en ocasiones una misma víctima aparecía bajo distintos conceptos. En todo caso, insistimos en que éstos no son valores definitivos pero los porcentajes que proponemos en adelante sufrirán muy escasa variación.

El reparto regional sería el siguiente:

\begin{tabular}{ccc}
\hline REGIÓN & VÍCTIMAS & PORCENTAJE \\
\hline Andalucía & 510 & 7.53 \\
Aragón & 525 & 7.75 \\
Asturias & 116 & 1.71 \\
Baleares & 59 & 0.87 \\
Cantabria & 157 & 2.32 \\
Castilla-La Mancha & 773 & 11.42 \\
Castilla-León & 32 & 0.47 \\
Cataluña & 2030 & 29.99 \\
Extremadura & 97 & 1.43
\end{tabular}

8 Seis mil ochocientos treinta y dos, de los cuales cuatro mil ciento ochenta y cuatro pertenecen al clero secular, incluidos doce obispos, un administrador apostólico y los seminaristas; dos mil trescientos sesenta y cinco son religiosos y doscientas ochenta y tres religiosas; Antonio MONTERO MORENO, Historia de la persecución..., 672.

Actas del I Congreso de Historia de la Iglesia y el Mundo Hispánico

Hispania Sacra 53 (2001) 


\begin{tabular}{crr} 
Galicia & 1 & 0.01 \\
Madrid & 1009 & 14.90 \\
Murcia & 71 & 1.05 \\
Valencia & 1028 & 15.18 \\
Vascongadas & 63 & 0.93 \\
No consta & 299 & 4.42 \\
\hline TOTAL & $\mathbf{6 7 7 0}$ & \\
\hline
\end{tabular}

A ellos habría que añadir, con toda propiedad, una muerte ocurrida en Francia:

«El Hno. marista Pablo Daniel Altabella, del Colegio Valdemia de Mataró, después de una odisea de prisiones y campos de trabajo forzado, acompañó al ejército rojo ejerciendo su apostolado hasta más allá de la frontera pirenaica, donde el 21-I-39, no puede reprimir una exclamación - ¡Gracias a Dios que, por fin, nos vemos libres de estos elementos! - . Le oyó un soldado rojo, aun sin desarmar por la gendarmería gala, y le asesinó con su último disparo»?.

Podemos hacer algunas precisiones acerca de la distribución regional y provincial de las víctimas:

\section{ANDALUCÍA Y EXTREMADURA}

\begin{tabular}{ccc}
\hline ProviNCIA & VíCTIMAS & PORCENTAJE \\
\hline Málaga & 141 & 23.23 \\
Jaén & 125 & 20.59 \\
Almería & 107 & 17.63 \\
Badajoz & 93 & 15.32 \\
Córdoba & 77 & 12.69 \\
Granada & 41 & 6.75 \\
Sevilla & 14 & 2.31 \\
Cádiz & 4 & 0.66 \\
Cáceres & 4 & 0.66 \\
Huelva & 1 & 0.16 \\
\hline ToTAL & $\mathbf{6 0 7}$ & \\
\hline
\end{tabular}

9 Fernando Gómez CATón, La Iglesia de los mártires..., II, 233.

Actas del I Congreso de Historia de la Iglesia y el Mundo Hispánico Hispania Sacra 53 (2001) 
En la tabla anterior se observa la dureza que alcanzó la persecución religiosa en algunas zonas del sur mientras que las provincias que pasaron pronto a formar parte de la retaguardia nacional sufrieron en muchísima menor proporción este fenómeno. Los valores más altos los ocupan cuatro provincias que quedaron en zona republicana en su integridad, al menos durante algún tiempo: Málaga, Jaén, Almería y Badajoz. Un segundo bloque está formado por Córdoba y Granada (que estuvieron divididas) mientras que en Sevilla, Cádiz y Huelva (donde el control republicano fue más transitorio) el número de víctimas supone un porcentaje muy reducido sobre el total.

\section{FRANJA CENTRAL}

\begin{tabular}{ccc}
\hline PROVINCIA & VÍCTIMAS & PORCENTAJE \\
\hline Madrid & 1009 & 55.62 \\
Toledo & 328 & 18.08 \\
Ciudad Real & 208 & 11.47 \\
Cuenca & 99 & 5.46 \\
Guadalajara & 95 & 5.24 \\
Albacete & 43 & 2.37 \\
Ávila & 20 & 1.10 \\
León & 6 & 0.33 \\
Burgos & 4 & 0.22 \\
Palencia & 2 & 0.11 \\
\hline ToTAL & $\mathbf{1 8 1 4}$ \\
\hline
\end{tabular}

Las provincias de Castilla-León quedaron en su práctica totalidad en zona nacional desde los primeros momentos de la guerra por lo que apenas tuvieron víctimas si se exceptúan los 20 sacerdotes de Ávila (comarcas de Arenas de San Pedro y Cebreros) y algunos otros en el norte de León y Burgos ${ }^{10}$ :

«En la cuenca del Torío y en toda la comarca leonesa colindante con el frente existían en julio y agosto de 1936 franjas de terreno auténticamente indecisas, que unos días eran tierra de nadie y en otras ocasiones convertíanse en campo de disputa para las avanzadillas de ambos bandos. Las poblaciones enclavadas en esta indiscriminada línea de fuego difícilmente pueden encasillarse entre las directamente sometidas a persecución religiosa. A lo más, padecían la incursión fugaz de pequeños contingentes de milicianos que hacían y deshacían a su antojo mientras duraba su estancia en el lugar. Víc-

10 Las dos muertes que aparecen en Palencia se produjeron en octubre de 1934.

Actas del I Congreso de Historia de la Iglesia y el Mundo Hispánico

Hispania Sacra 53 (2001) 
timas de tales incursiones fueron algunos párrocos del agro leonés, varias de cuyas muertes se debieron en exclusiva a su celo por las cosas de Dios»11.

Toledo alcanza el más elevado porcentaje de víctimas religiosas de la región manchega mientras que en toda la franja central -y en toda España- el lugar más destacado lo ocupa Madrid, provincia en la que se superaron las 1000 bajas.

Acerca del reparto de las muertes ocurridas en la capital de España cabe precisar que, como refleja la siguiente tabla, un $68,52 \%$ de los sacerdotes, religiosos y religiosas asesinados en Madrid en fecha conocida lo fueron en los meses anteriores a las matanzas de Paracuellos, el $27.51 \%$ pereció en este lugar y sólo un $3,96 \%$ encontró la muerte una vez que se interrumpieron estas «sacas» masivas y hasta el final de la guerra. Por lo tanto, cuando tuvieron lugar los sucesos de Paracuellos, ya había sido eliminado un número muy importante de eclesiásticos mientras que buena parte de los que quedaban en las cárceles porque habían sobrevivido a los paseos y a las sacas del período anterior fueron literalmente exterminados en noviembre de 1936.

\begin{tabular}{ccc}
\hline FECHA & VíCTIMAS & PORCENTAJE \\
\hline jul-36 & 128 & 15.86 \\
ago-36 & 203 & 25.15 \\
sep-36 & 91 & 11.28 \\
oct-36 & 55 & 6.82 \\
1-noviembre al 6-noviembre & 11 & 1.36 \\
«Paracuellos» (7-noviembre & 222 & 27.51 \\
al 4-diciembre) & & \\
Entre las mismas fechas en otros lugares & 65 & 8.05 \\
Hasta el 31-diciembre & 11 & 1.36 \\
1937 & 17 & 2.11 \\
1938 & 3 & 0.37 \\
1939 & 1 & 0.12 \\
\hline
\end{tabular}

\section{CATALUÑA Y LEVANTE}

\begin{tabular}{ccc}
\hline ProvinCIA & VíCTIMAS & PORCENTAJE \\
\hline Barcelona & 1030 & 32.31 \\
Valencia & 575 & 18.04 \\
Lérida & 433 & 13.58
\end{tabular}

11 Antonio MONTERO MORENO, Historia de la persecución...; 590.

Actas del I Congreso de Historia de la Iglesia y el Mundo Hispánico Hispania Sacra 53 (2001) 


\begin{tabular}{crc} 
Castellón & 347 & 10.88 \\
Tarragona & 318 & 9.97 \\
Gerona & 249 & 7.81 \\
Alicante & 106 & 3.32 \\
Murcia & 71 & 2.23 \\
Baleares & 59 & 1.85 \\
\hline TOTAL & $\mathbf{3 1 8 8}$ & \\
\hline
\end{tabular}

En Cataluña y la franja levantina se encuentran las provincias más castigadas por la persecución religiosa. Los porcentajes más altos se alcanzaron en Barcelona y Valencia, aunque no faltaron abundantes víctimas en el resto de un territorio que formó parte de la retaguardia republicana hasta los últimos momentos de la guerra.

4. ARAGÓN

\begin{tabular}{ccc}
\hline PROVINCIA & VÍCTIMAS & PORCENTAJE \\
\hline Huesca & 358 & 68.19 \\
Teruel & 140 & 26.67 \\
Zaragoza & 27 & 5.14 \\
\hline TOTAL & $\mathbf{5 2 5}$ & \\
\hline
\end{tabular}

Una vez superada la indecisión de los primeros momentos, la región aragonesa quedó dividida entre los dos bandos. En la zona sometida a control de los republicanos, el derramamiento de sangre entre los eclesiásticos fue muy abundante debido, en buena medida a lo ocurrido en la ciudad y diócesis de Barbastro (Huesca).

\section{FRANJA NORTE}

\begin{tabular}{ccc}
\hline ProviNCIA & VíCTIMAS & PORCENTAJE \\
\hline Cantabria & 157 & 46.87 \\
Asturias & 115 & 34.33 \\
Vizcaya & 55 & 16.42 \\
Guipúzcoa & 6 & 1.79 \\
Álava & 2 & 0.60 \\
\hline TotAL & $\mathbf{3 3 5}$ & \\
\hline
\end{tabular}

Actas del I Congreso de Historia de la Iglesia y el Mundo Hispánico

Hispania Sacra 53 (2001) 
Varias fueron las provincias del norte que se vieron afectadas por la persecución: Asturias (entre cuyas víctimas se incluyen las producidas con ocasión de la Revolución de Octubre), Cantabria (donde todo adquirió un carácter auténticamente sistemático y premeditado), Álava, Guipúzcoa y Vizcaya. Estas últimas (integradas en la diócesis de Vitoria) representan sin duda un caso singular pues era el único lugar de la España republicana donde los sacerdotes seguían ejerciendo su ministerio, el culto se desarrollaba con cierta normalidad, los capellanes acompañaban al ejército y la organización eclesiástica no sufrió quebranto aunque la situación era completamente atípica pues la diócesis estaba territorialmente dividida y el obispo Múgica se encontraba en el exilio por sugerencia del Gobierno de Burgos. Sin embargo esto no evitó el asesinato de unos 60 sacerdotes y religiosos, hecho que se ha atribuido a los representantes del Frente Popular pero que pone de manifiesto que en el aspecto religioso tampoco la retaguardia vasca fue un paraíso ${ }^{12}$.

El reparto entre clero secular, regular y religiosas tampoco es homogéneo como puede verse en los porcentajes regionales del siguiente cuadro:

\begin{tabular}{cccccc}
\hline \multirow{2}{*}{ GruPo } & $\begin{array}{c}\text { ARAGón } \\
\text { CATALUÑ }\end{array}$ & CENTRO & LEVANTE & NORTE & SUR \\
\hline Clero secular & 60.67 & 50.06 & 65.11 & 57.87 & 76.44 \\
Clero regular & 36.91 & 44.38 & 27.46 & 41.84 & 22.73 \\
Religiosas & 2.23 & 5.57 & 7.43 & 0.3 & 0.82 \\
\hline
\end{tabular}

12 El cabildo de la Catedral de Vitoria precisaba en julio de 1937: « $1^{\circ}$. La inmensa mayoría de los sacerdotes se ha visto obligado a vestir de seglar aun en el mismo Bilbao; $2^{\circ}$. Muchos han sido vejados, perseguidos y encarcelados sin proceso ni juicio alguno; $3^{\circ}$. Muchos han sido asesinados, sin que se sepa de castigo alguno impuesto a los culpables; $4^{\circ}$. Las casas de no pocos de ellos han sido allanadas y saqueadas a cualquier hora del día y de la noche; $5^{\circ}$. No se ha llevado públicamente el Santo Viático, ni se han conducido solemnemente los cadáveres, fuera de algunos de personas destacadas, contrastando esto con la asistencia de autoridades vascas a una porción de entierros civiles de jefes de milicianos muertos en el frente; $6^{\circ}$. Apenas ha habido cultos vespertinos ni predicación en muchas iglesias; $7^{\circ}$. Las mujeres han tenido que acudir a ellos y llevar la mantilla puesta por las calles, so pena de ser insultadas groseramente. $8^{\circ}$. Las iglesias han estado contra costumbre cerradas durante gran parte del día; $9^{\circ}$. Bastantes han sido convertidas en almacenes de víveres, cuarteles, salas de baile y hasta prostíbulos, como las de Ubidea y Ochandiano, etc., no disponiendo algunas poblaciones ni de las precisas para satisfacer la piedad de los fieles; $10^{\circ}$. Se han proferido blasfemias horribles, procaces dicterios contra la Iglesia y las jerarquías católicas desde la emisora del Gobierno vasco, establecida en el mismo palacio presidencial. Junto a estos hechos, ¿qué significa la apertura de un seminario, la exención de los sacerdotes del cumplimiento de las leyes militares y algunos otros, de más apariencia que realidad?» cit. por Manuel RUBIO CABEZA, Diccionario de la guerra civil española, Madrid, Planeta, 1987, 194.

Actas del I Congreso de Historia de la Iglesia y el Mundo Hispánico

Hispania Sacra 53 (2001) 
En todas las regiones, como es lógico, predominan los asesinatos de sacerdotes seculares mientras que el número de religiosos es especialmente elevado en el Centro, Aragón-Cataluña y el Norte. En el primer caso, esto se explica por las matanzas de Paracuellos ${ }^{13}$ y por las comunidades de frailes del mismo Madrid y diversos pueblos, sobre todo de Toledo y Ciudad Real, que fueron eliminadas en su práctica totalidad (Toledo capital, Alcázar de San Juan, Manzanares, Daimiel...). En Aragón y Cataluña hay que referirse a lo ocurrido en Barbastro, Barcelona, Lérida y Cervera pues sólo en estas cuatro localidades se concentra el 53\% de los religiosos asesinados en toda la región. En el norte fueron Santander y Gijón las ciudades más castigadas mientras que el resto de las víctimas fueron muy dispersas.

Las regiones en que fueron fusiladas más religiosas fueron Madrid (con la práctica totalidad de los casos ocurridos en la zona centro) y Valencia, donde los sucesos fueron realmente trágicos pues, dejando a un lado las muertes aisladas, fueron exterminadas los siguientes grupos de monjas:

- 5 Escolapias de Valencia (Valencia, 8-agosto-1936)

- 9 Carmelitas de la Caridad de Cullera (Valencia, 19-agosto-1936).

- 15 Hermanas de la Doctrina Cristiana de Mislata (Paterna, 20-noviembre1936).

- 11 Carmelitas de la Caridad de Valencia (Paterna, 24-noviembre-1936).

- 5 Hijas de la Caridad de Bétera (Valencia, 11-diciembre-1936).

Por el contrario, en las provincias del Norte y del Sur, el porcentaje de religiosas sobre el total de víctimas eclesiásticas no llega al $1 \%$.

\section{PERSECUCIÓN RELIGIOSA Y REPRESIÓN}

No se puede ignorar que las muertes ocasionadas por la persecución religiosa desencadenada en España entre 1931-1939, coincidieron en el tiempo y en el espacio con un fenómeno de mayor amplitud: la represión llevada a cabo por dos bandos en lucha entre sus oponentes, y -más en concreto- la represión ejercida por los republicanos ${ }^{14}$. Hablar de persecución religiosa obliga a hablar de represión y viceversa.

\footnotetext{
13 En las diversas sacas que terminaron en esta localidad madrileña perecieron 71 agustinos, 22 hermanos de San Juan de Dios, 16 oblatos, 14 hermanos de La Salle, 13 dominicos y, en menor número, miembros de otras órdenes religiosas.

14 Adelantamos ya que únicamente en el bando republicano hubo persecución religiosa. La quincena de eclesiásticos ejecutados por los tribunales militares del ejército sublevado en Vascongadas lo 
Podemos poner en relación el número de víctimas de la persecución religiosa con el total de víctimas de la represión republicana ${ }^{15}$ intentando descubrir así cuál fue el reparto de todas estas muertes sobre el mapa y qué regiones resultaron más afectadas. Dejamos aparte el caso de Galicia porque sólo se produjo la muerte de un sacerdote:

«[En Piñeiro, La Coruña] invadieron la casa del médico señor Otero, y dieron muerte de un modo salvaje a un hijo suyo y al cura de Camouco, que allí se había refugiado» 16 .

\begin{tabular}{ccc}
\hline REGIÓN & REPRESIÓN REPUBLICANA & PORCENTAJE \\
\hline Madrid & 14898 & 26.06 \\
Andalucía & 9231 & 16.15 \\
Cataluña & 8826 & 15.44 \\
Castilla-La Mancha & 7840 & 13.71 \\
Valencia & 6351 & 11.11 \\
Aragón & 3509 & 6.14 \\
Asturias & 1493 & 2.61 \\
Extremadura & 1490 & 2.61 \\
Murcia & 1129 & 1.97 \\
Vascongadas & 831 & 1.45 \\
Castilla-León & 631 & 1.10 \\
Cantabria & 609 & 1.07 \\
Baleares & 331 & 0.58 \\
\hline
\end{tabular}

Por lo que se refiere a la represión republicana, el número más elevado de víctimas se alcanzó en Madrid. El hecho tiene toda lógica pues en la capital de España se inició el terror en fechas muy tempranas, continuó con la actividad de las checas, los «paseos» y las «sacas» y tuvo una trágica culminación en las matanzas sistemáticas de noviembre de 1936 que vaciaron las cárceles madrileñas.

En cifras absolutas siguen a Madrid, Andalucía, Cataluña, Castilla-La Mancha y Valencia (todas con porcentajes superiores al 10\%) mientras que alcan-

\footnotetext{
fueron por motivaciones exclusivamente políticas (cfr. Anastasio GRANADOS, El Cardenal Goma. Primado de España, Espasa Calpe, Madrid, 1969, 145ss).

15 Estas cifras se obtienen en su mayoría a partir de los datos del Instituto Nacional de Estadística y las hemos propuesto en el libro ya citado Paz, piedad, perdón... y verdad. Ya sabemos que la fiabilidad de estos números no es exhaustiva pero podemos estar ante un orden de magnitud correcto.

16 Joaquín ARRARaS (dir.), Historia de la Cruzada Española, IV, Publicaciones españolas, Madrid, 1941, 65. Se trataba de don Manuel Landeiro Muiños (21-julio-1936).
}

Actas del I Congreso de Historia de la Iglesia y el Mundo Hispánico

Hispania Sacra 53 (2001) 
zan valores más bajos aquellas regiones cuyo territorio -excepto en el caso de Murcia- quedó dividido entre los dos bandos.

Más gráficamente, sobre el mapa se define un núcleo situado al lado oriental del frente aragonés (Huesca, Teruel, Castellón, Valencia, Tarragona, Barcelona,...) En el centro y al sur se dibuja otro sector duramente castigado (Albacete, Cuenca, Málaga, Córdoba, Jaén,...) sin olvidar el norte y las provincias en las que el dominio republicano fue más discontinuo (Granada, Zaragoza, Sevilla, Ảvila, ...). Al margen de la represión republicana quedó ese gran «pulmón» de la retaguardia nacional formado por Galicia, Castilla-León, La Rioja y Navarra.

Por lo que se refiere a la incidencia de la persecución religiosa partimos del siguiente cuadro:

\begin{tabular}{cccc}
\hline REGIÓN & REPR. REPUBLICANA & PERS. RELIGIOSA & PORCENTAJE \\
\hline Andalucía & 9231 & 510 & 5.52 \\
Aragón & 3509 & 525 & 14.96 \\
Asturias & 1493 & 115 & 7.70 \\
Baleares & 331 & 59 & 17.82 \\
Cantabria & 609 & 157 & 25.78 \\
Castilla-La & 7840 & 773 & 9.86 \\
Mancha & & & \\
Castilla-León & 631 & 32 & 5.07 \\
Cataluña & 8826 & 2030 & 23.00 \\
Extremadura & 1490 & 97 & 6.51 \\
Madrid & 14898 & 1009 & 6.77 \\
Murcia & 1129 & 71 & 6.29 \\
Valencia & 6351 & 1028 & 16.19 \\
Vascongadas & 831 & 62 & 7.46 \\
No consta & & 302 & \\
\hline ToTAL & $\mathbf{5 7 1 6 9}$ & $\mathbf{6 7 7 0}$ & $\mathbf{1 1 . 8 4}$ \\
\hline
\end{tabular}

Como se puede apreciar en la distribución de las víctimas, la persecución fue más intensa, lógicamente, en aquellas zonas donde la represión en general fue más dura, pero puede decirse que abarca la práctica totalidad del territorio en que se extendió la represión republicana. Los mayores porcentajes se alcanzan en Cataluña y en la franja central mientras que el norte resultó mucho menos castigado (sobre todo porque en la diócesis de Vitoria - con la provincia de Álava en retaguardia nacional- la persecución religiosa revistió caracteres peculiares y el número de víctimas no fue tan elevado como en otros lugares). En 
todo caso el promedio nacional es significativo (en torno al 11\%) y demuestra que sin duda fueron los eclesiásticos el sector proporcionalmente más castigado por la represión republicana que queda así necesariamente caracterizada por sus motivaciones antirreligiosas.

A la hora de valorar las pérdidas no ya por provincias sino por diócesis y tratando de buscar el impacto de la persecución sobre el clero secular, puede resultar útil el siguiente cuadro en el que no se han incluido aquellas diócesis en que el número de víctimas fue muy bajo:

\begin{tabular}{cccc}
\hline ZONA & $\begin{array}{c}\text { SACERDOTES MUERTOS } \\
\text { (DIÓCESIS CON MÁS DE } \\
\text { 20 VÍCTIMAS) }\end{array}$ & $\begin{array}{c}\text { ClERo } \\
\text { INCARDINADo }\end{array}$ & PORCENTAJE \\
\hline Andalucía y & 534 & 2836 & 18.83 \\
Extremadura & & 1384 & 20.38 \\
Aragón & 282 & 5144 & 29.86 \\
Cataluña & 1536 & 3211 & 28.00 \\
Franja central & 899 & 2305 & 24.95 \\
Levante & 575 & 3760 & 6.70 \\
Norte & 252 & $\mathbf{1 8 6 4 0}$ & $\mathbf{2 1 . 8 8}$ \\
\hline Total & $\mathbf{4 0 7 8}$ & & \\
\hline
\end{tabular}

Como ya vimos, en Cataluña y la región levantina es donde las víctimas eclesiásticas alcanzan un porcentaje más elevado sobre el total de bajas ocasionadas por la represión, el norte se sitúa en una posición intermedia mientras que en el sur y en la franja central los valores son aún más bajos. Las diócesis que perdieron un número más elevado de sus efectivos sacerdotales, por encima o en torno al $50 \%$ fueron Barbastro $(83,70 \%)$, Lérida, Tortosa, Segorbe, Menorca y Toledo.

\section{CRONOLOGÍA}

La relación que hemos establecido entre persecución religiosa y represión republicana resulta especialmente clara a la hora de estudiar cómo se distribuyeron las víctimas a lo largo de los meses que duró el conflicto. Si ya hemos visto la coincidencia en el espacio que hay entre represión y persecución religiosa, ahora tendremos que comprobar esa misma identificación en el tiempo. 
A partir de un criterio claro, la evolución militar de la guerra, se pueden definir varias situaciones en las que la periodización de la violencia es distinta:

1. Zonas que estuvieron poco tiempo bajo el control de la República y fueron tomadas por las columnas nacionales en los primeros meses de la guerra, antes de estabilizarse los frentes.

Sería el caso de las provincias andaluzas de Cádiz, Huelva y Sevilla, y parte de Córdoba, Badajoz, Ávila, Toledo, Madrid, Guadalajara o Guipúzcoa.

En algunos lugares de los citados la violencia se desató de forma temprana pero en general, la pronta ocupación por las tropas nacionales impidió que alcanzaran valores demasiado elevados y que se prolongaran más allá de finales de octubre de 1936.

2. Zonas que permanecieron durante largo tiempo en territorio republicano y fueron ocupadas paulatinamente a los largo de los restantes años de la guerra.

En esta situación se encuentran las zonas de Granada y Málaga, cuya capital fue tomada en febrero de 1937, las ocupadas con ocasión de la Campaña del Norte (Vascongadas, Santander, Asturias y las comarcas del norte de Burgos, León y Palencia) y las zonas que cayeron con ocasión de la batalla de Aragón y la ofensiva sobre el Mediterráneo a partir de marzo de 1938 (la retaguardia republicana de Huesca, Zaragoza y Teruel y partes de Lérida y Castellón). Por último habría que referirse a Cataluña (ocupada definitivamente a comienzos de 1939) y a pequeñas partes de otras provincias que pasaron a zona nacional en operaciones de menor alcance como el cierre de la Bolsa de La Serena (Badajoz, julio-1938).

3. Zonas ocupadas en la que se llamó «ofensiva de la Victoria» en marzo de 1939.

Al término de la guerra civil, los nacionales tomaron las partes de Granada, Córdoba Badajoz, Toledo, Madrid y Guadalajara que aún permanecían en zona republicana así como las provincias de Albacete, Alicante, Almería, Ciudad Real, Cuenca, Jaén, Murcia y Valencia.

Ambas zonas, las que fueron ocupadas progresivamente y las que permanecieron en zona republicana hasta el final de la guerra, tuvieron un comporta- 
miento semejante y las represalias se produjeron en una cadencia acusadamente piramidal, es decir, con un máximo en determinado mes y un descenso acusado hasta los primeros meses de 1937. En el resto de 1937, 1938 y 1939, los hechos de violencia estarán, en la mayoría de los casos, en relación con acontecimientos puntuales.

Para toda España puede verse el reparto cronológico de las muertes de eclesiásticos en el siguiente cuadro:

\begin{tabular}{ccc}
\hline FECHA & VíCTIMAS & PORCENTAJE \\
\hline 0ctubre-1934 & 37 & 0.62 \\
jul-36 & 966 & 16.08 \\
ago-36 & 2213 & 36.83 \\
sep-36 & 1087 & 18.09 \\
oct-36 & 580 & 9.65 \\
nov-36 & 596 & 9.92 \\
dic-36 & 252 & 4.19 \\
ene-37 & 68 & 1.13 \\
feb-37 & 23 & 0.38 \\
mar-37 & 35 & 0.58 \\
abr-37 & 24 & 0.40 \\
may-37 & 21 & 0.35 \\
Resto-1937 & 45 & 0.75 \\
1938 & 44 & 0.73 \\
1939 & 17 & 0.28 \\
\hline
\end{tabular}

La fecha en que se sitúa el máximo de víctimas de la persecución religiosa oscila, según las zonas, entre los diversos meses del verano y el otoño de 1936 pero en la mayoría de las provincias fue agosto la que concentra las cifras más elevadas. Como excepciones, en Murcia y Vascongadas el mes en el que tuvieron lugar más muertes de eclesiásticos fue octubre y en Baleares, noviembre; en este mismo mes, en Madrid, mientras que en Cantabria, sería en diciembre y en Vizcaya en enero de 1937. Todos estos máximos hay que ponerlos en relación con otros tantos episodios represivos ocurridos en dichas fechas (matanzas de Paracuellos, asalto al Alfonso Pérez en Santander o a las cárceles de Bilbao, etc.).

A partir de diciembre de 1936 y de los primeros meses de 1937 hay un descenso progresivo del número de víctimas y desde mayo de ese mismo año, $\mathrm{y}$ hasta el final de la guerra, las cifras de eclesiásticos asesinados son ya muy reducidas aunque ello no quiere decir que terminara la persecución. En reali- 
dad es que los asesinatos en la retaguardia republicana (sin llegar nunca a desaparecer totalmente) remitieron notablemente, en buena parte debido a la adopción de mecanismos de control por parte del gobierno pero también «porque la depuración ya estaba hecha» ${ }^{17}$ y porque la represión se orientó hacia otras formas. En todo caso, entre junio de 1937 y marzo de 1939 hemos documentado un centenar de muertes que en numerosas ocasiones están relacionadas con eclesiásticos movilizados forzosamente y asesinados durante su estancia en los frentes o de presos ejecutados en la retirada del ejército republicano ${ }^{18}$.

Para ver todo esto con más detalle, interesa comprobar la extensión de la violencia anticlerical en los primeros momentos de la guerra. Sorprenderá su rápida expansión y su lento apagarse.

El mismo 19-julio-1936 hay muertes de eclesiásticos en Barcelona y Sevilla; el 20-julio se producen en las provincias de Barcelona, Córdoba, Jaén, Lérida, Madrid y Tarragona; y en días sucesivos se extenderán al resto, de manera que al llegar el 30-julio habían tenido lugar asesinatos de sacerdotes y religiosos en 30 provincias. En cambio, habrá que esperar al mes siguiente para que se produzcan crímenes de esta naturaleza en las provincias de Almería (17-agosto), Burgos (15-agosto), Cádiz, Cantabria (2-agosto), Murcia (1-agosto) y Vizcaya (29-agosto).

El descenso fue lento, en enero-1937 todavía hubo asesinatos en un total de 13 provincias; en febrero, en 8; y así sucesivamente hasta que al llegar a finales de 1938 prácticamente sólo ocurrían asesinatos de eclesiásticos en Cataluña y Madrid. Entre enero y marzo del último año de la guerra los escenarios serían las provincias de Barcelona, Lérida y Gerona (en enero-febrero) y, ya en marzo, los frentes de Badajoz, Castellón, Cuenca y Madrid. La última muerte de la que tenemos noticia es la del oblato Macario Mancebo (El Escorial, 27marzo-1939).

17 Ramón SALAS LARRAZÁBAL, La represión en territorio republicano en Aportes 8 (1988) 58.

18 El caso más conocido, no el único, es el del Obispo de Teruel Beato Anselmo Polanco Fontecha, su Vicario general Beato Felipe Ripoll Morata y el canónigo don Javier García Blasco, que fueron hechos prisioneros con ocasión de la toma de la capital turolense por los republicanos en enero de 1938 y que, después de recorrer varias cárceles fueron asesinados junto con otros detenidos el 7febrero-1939 durante la retirada de Cataluña. También cabe referirse aquí a dos sacerdotes hechos prisioneros junto a las tropas a las que asistían espiritualmente y fusilados, se trata de don Juan Ruiz Gimeno (Quinto, 24-agosto-1937) y del capellán del Tercio de Almogávares, defensores del Seminario de Belchite, don Juan Lou Miñana (Híjar, 1-septiembre-1937).

Actas del I Congreso de Historia de la Iglesia y el Mundo Hispánico Hispania Sacra 53 (2001) 


\section{LAS FORMAS DE LA PERSECUCIÓN RELIGIOSA}

En líneas generales es posible definir dos grandes formas de represión:

\section{1. «Violencia revolucionaria»}

En los primeros momentos, las resistencias de numerosas poblaciones (Madrid, Guadalajara, Albacete, Caspe, ...) y de cuarteles de la Guardia Civil en provincias como Granada y Huelva, acabaron con el fusilamiento de los defensores -miembros de la Benemérita y paisanos- que no pudieron evacuar las posiciones y fueron hechos prisioneros y de otros que no habían tenido responsabilidad en el alzamiento. Coincidiendo cronológicamente en el tiempo se desató una oleada de violencia en las zonas que fueron controladas desde el principio por la República y donde no existieron movimientos favorables a la sublevación. En todos estos grupos era norma común la presencia de religiosos y sacerdotes.

Cuando el estado de la investigación lo permita será interesante detallar -en el caso de que sea posible- las circunstancias en que se produjeron los asesinatos de eclesiásticos pues, evidentemente, no responden a los mismos planteamientos y responsabilidades los llamados «paseos» o ejecuciones arbitrarias e individuales que una matanza colectiva en la que el número de víctimas es mucho mayor. Siempre será interesante ver cuáles fueron los grupos en los que se concentro un mayor número de víctimas de condición religiosa $\mathrm{y}$, en todo caso, es posible ya sistematizar las siguientes situaciones:

1) Muertes aisladas: cuando los asesinatos fueron muy selectivos y afectaron a personas concretas o a pequeños grupos (menos de cinco personas) con alguna vinculación entre sí (familiares, paisanos, compañeros de cautiverio, militancia política...).

2) Grupos formados sólo por eclesiásticos: pueden ser más o menos numerosos.

3) Grupos formados por eclesiásticos y seglares:

- Matanzas indiscriminadas: especialmente en momentos de especial tensión como podían ser los previos a la llega de las tropas nacionales.

- Grupos reducidos (entre 5 y 15 personas): en los que predominaban generalmente las denominadas «fuerzas vivas» de la localidad (propietarios, profesionales liberales, sacerdotes, etc.).

- Fusilamientos masivos: en lugares donde la represión alcanzó grandes proporciones y afectó a todas las clases sociales. 


\section{2. «Terror institucionalizado»}

Desde los primeros momentos y especialmente a partir de 1937 en Madrid, en la retaguardia costera del Mediterráneo y en otros lugares la represión presentará otras formas y contará con organismos más especializados. Es la época de las «checas», del S.I.M. y de los campos de trabajo. En relación con esta fase puede verse lo que dijimos acerca de las bajas en 1937-1939.

\section{Un apunte sobre los incendios, saqueos y profanaciones}

Como es bien sabido, los edificios destinados al culto (iglesias, ermitas y conventos) fueron por regla general profanados y después convertidos en cárceles, casas del pueblo, almacenes, garajes, cuadras, etc. Los sacrilegios, burlas, parodias de las ceremonias religiosas y los hechos incalificables con las imágenes y el Santísimo Sacramento, fueron escenas corrientes.

Realmente es difícil un balance acerca de los efectos de esta destrucción. En principio puede ser interesante constatar que en este proceso, no todo fue «espontaneidad» revolucionaria:

\footnotetext{
«La ejecución material de tan vastos atropellos, lo mismo en la capital de la nación que en las ciudades y aldeas de provincias, fue mitad organizada, mitad anárquica, a veces estrictamente oficial y en ocasiones desbordando al poder constituido. Ya sabemos que, al menos para la incautación de los templos y para la suspensión del culto, se contaba con apoyaturas legales más que suficientes»19.
}

Con Decreto del 27-julio-1936, el Gobierno había ordenado la ocupación en el plazo de cinco días «de todos aquellos edificios, con el material científico y pedagógico, que las Congregaciones religiosas tenían dedicados a la enseñanza el 14 de abril de 1931, y los que, aun no dedicados a ella, estuviesen actualmente desocupados». El 11 de agosto fueron clausurados por otro Decreto todos los establecimientos religiosos existentes en España cuyos titulares hubieran intervenido de algún modo «en el presente movimiento insurreccional, participando en él directa o indirectamente, o favoreciendo, o auxiliando, cualquiera que sea la manera empleada, a los rebeldes o sediciosos». El 12 de agosto se ordenó la incautación de todas las instituciones de beneficencia dirigidas por religiosos.

Como consecuencia de estas disposiciones todo aquello que se había producido en los días anteriores quebrantando la ley y el derecho quedaba refrendado aunque la mayoría de los edificios e instituciones incautadas no lo habían

19 Antonio MONTERO MORENO, Historia de la persecución..., 637. 
sido por el Estado sino por los grupos políticos y sindicales que siguieron ocupándolos y muy grande fue también la parte de esos bienes, especialmente los de más valor histórico y artístico, que ya habían sido destruidos o lo serían en los meses siguientes

La relación de pérdidas de obras religiosas de gran valor artístico, y en la mayoría de las ocasiones ni siquiera catalogadas, sería muy elevada y apenas resultaría significativo citar algunos de los casos más notorios ${ }^{20}$ como el monumento al Sagrado Corazón de Jesús en el Cerro de los Ángeles (Getafe) que fue volado con dinamita el 7 de agosto de 1936 después de ser asaltados los edificios religiosos que le circundaban. En Castellón de la Plana, en los primeros días del mismo mes fue asaltada la iglesia arciprestal de Santa María, Monumento nacional, quemando en una hoguera todas las imágenes, objetos sagrados y archivo; después de alguna discusión, el Ayuntamiento acordó la demolición del templo que se llevó a efecto. Especialmente afectadas resultaron algunas catedrales como la de San Isidro de Madrid, Jaén, Vich y Cuenca. Y en Toledo se incautaron el 4 de septiembre de 1936 «cumpliendo una orden verbal dada por el Excelentísimo Sr. D. José Giral, Presidente del Consejo de Ministros», -según figura en el acta- de la mayor parte del Tesoro catedralicio, desapareciendo objetos notables, aunque la rápida ocupación por las tropas nacionales de Toledo impidió la pérdida de otras joyas valiosas como la célebre Custodia de Enrique de Arfe que ya estaba desmontada así como los cuadros de la Catedral.

De nuevo puede resultar interesante una sistematización de los datos obtenidos de acuerdo con los siguientes criterios:

1) Intento fracasado de incendio, especialmente en los años de la Segunda República y en aquellos lugares en que el dominio republicano no llegó a consolidarse y solamente tuvieron lugar hechos esporádicos en los primeros días.

2) Edificios incautados y/o destinado a otros usos: dedicados a usos profanos pero sin sufrir daños de importancia en su contenido litúrgicoartístico ni en su fábrica.

3) Edificios parcialmente incendiados y/o saqueados: cuando los daños no alcanzaron a la totalidad del contenido del templo por no haberse realizado una destrucción sistemática, haberse ocultado los objetos de más valor o cualquier otra circunstancia.

20 Cfr. Joaquín ARRARAS, (dir.), Historia de la Cruzada Española, III-VI y La dominación roja en España, Ministerio de Justicia, Madrid, 1943, pp. 193-200.

Actas del I Congreso de Historia de la Iglesia y el Mundo Hispánico

Hispania Sacra 53 (2001) 
4) Interior totalmente destruido: desaparición de todos los retablos, imágenes, objetos litúrgicos ...

5) Edificios totalmente destruidos: cuando, además de lo anterior, se producen daños importantes en la fábrica (generalmente, destrucción de techumbre y en algún caso demolición total).

Como conclusión de todo lo que hemos venido exponiendo en este trabajo valgan unas impresiones acerca de la extensión, incluso material, de la persecución religiosa desencadenada en España durante aquellos años. La dureza alcanzada por las manifestaciones de este fenómeno, justifican con creces el esfuerzo todavía necesario para alcanzar su mejor conocimiento histórico.

«Quien destroza una imagen de la Virgen, quema un retablo o pisotea unos corporales, difícilmente puede escudarse en reivindicaciones clasistas o imperativos de guerra. No hay duda de que eso que hemos venido llamando "persecución religiosa» se nos muestra más plásticamente en millares de templos destruidos, Cristos mutilados y parodias sacrílegas, que en las ráfagas del paredón nocturno, donde podían mezclarse con los justos algunos o muchos pecadores...Aunque les falte a los objetos inanimados la condición indispensable de padecer consciente y libremente, resalta, en cambio, en su aniquilamiento el odio a lo que está detrás, a Dios, que representan, o, al menos, a la fe humana en ese Dios y en la Iglesia por Él fundada» 21 .

\section{PERSECUCIÓN RELIGIOSA EN ESPAÑA. GRUPOS DE VÍCTIMAS}

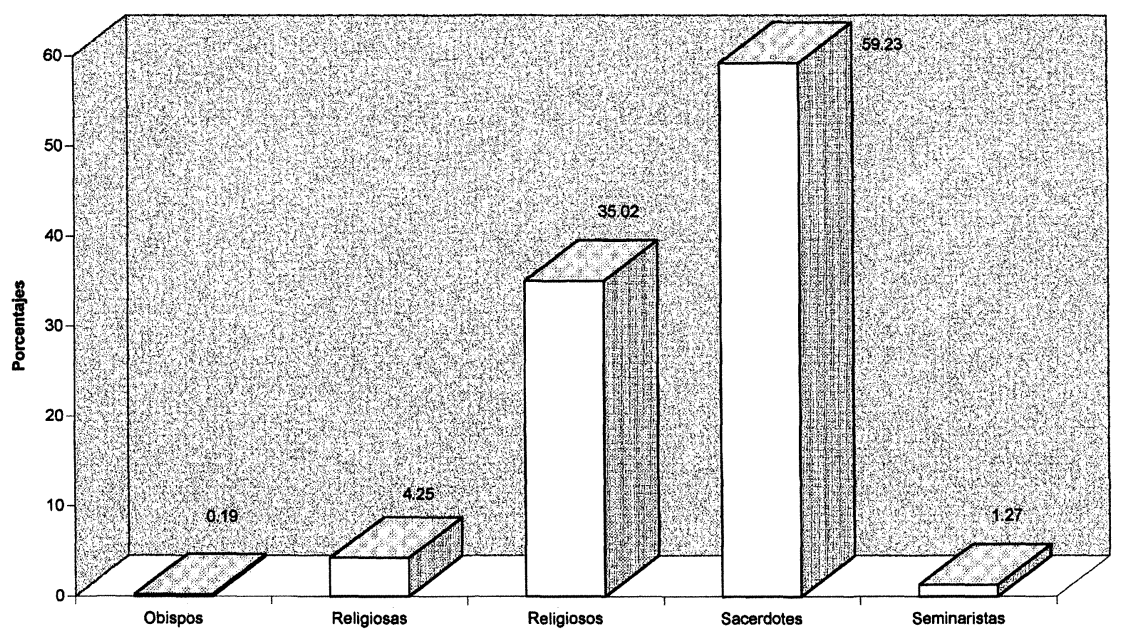

21 A. MONTERO MORENO, Historia de la persecución..., 627.

Actas del I Congreso de Historia de la Iglesia y el Mundo Hispánico

Hispania Sacra 53 (2001) 
PERSECUCIÓN RELIGIOSA EN ESPAÑA. GRUPOS DE VÍCTIMAS POR REGIONES

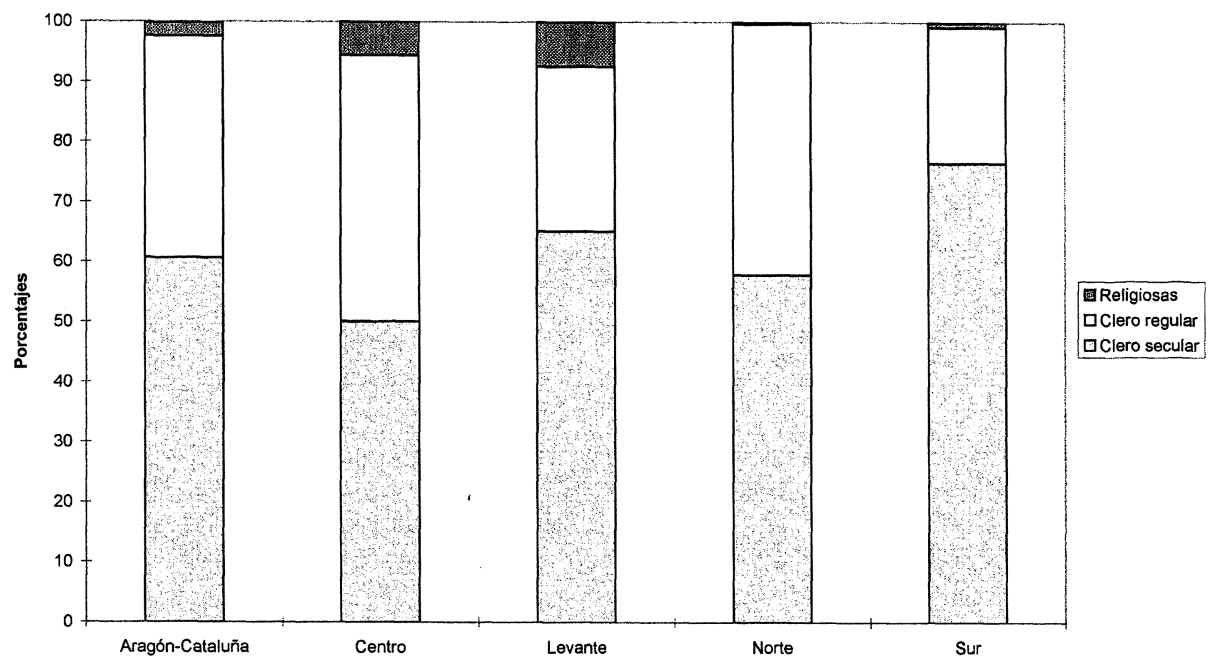

PERSECUCIÓN RELIGIOSA EN ESPAÑA. REPARTO REGIONAL



Actas del I Congreso de Historia de la Iglesia y el Mundo Hispánico Hispania Sacra 53 (2001) 


\section{REPRESIÓN REPUBLICANA-PERSECUCIÓN RELIGIOSA CIFRAS ABSOLUTAS}

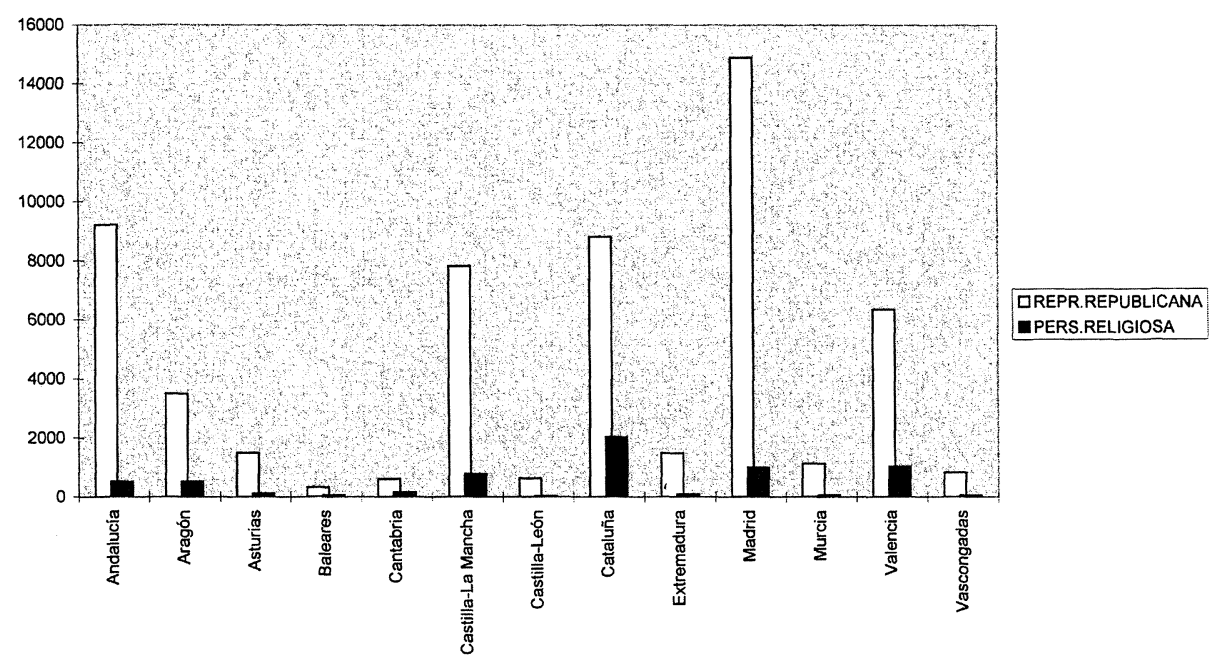

\section{REPRESIÓN REPUBLICANA-PERSECUCIÓN RELIGIOSA PORCENTAJES}

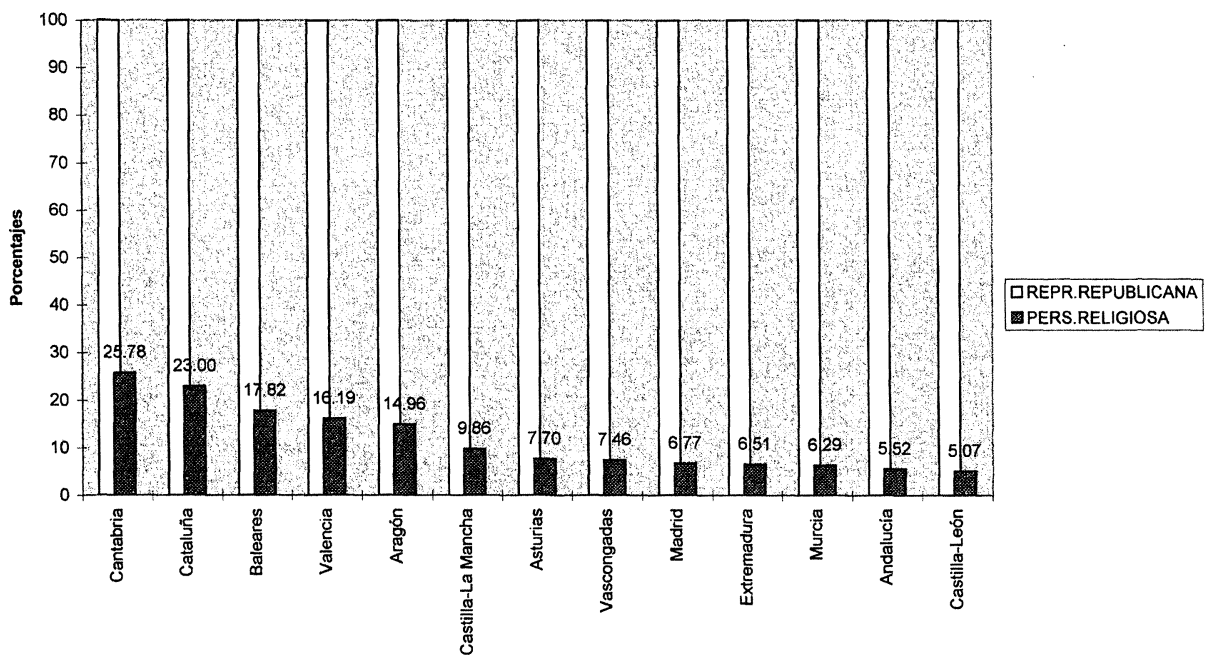

Actas del I Congreso de Historia de la Iglesia y el Mundo Hispánico Hispania Sacra 53 (2001) 
PERSECUCIÓN RELIGIOSA EN ESPAÑA. CRONOLOGÍA

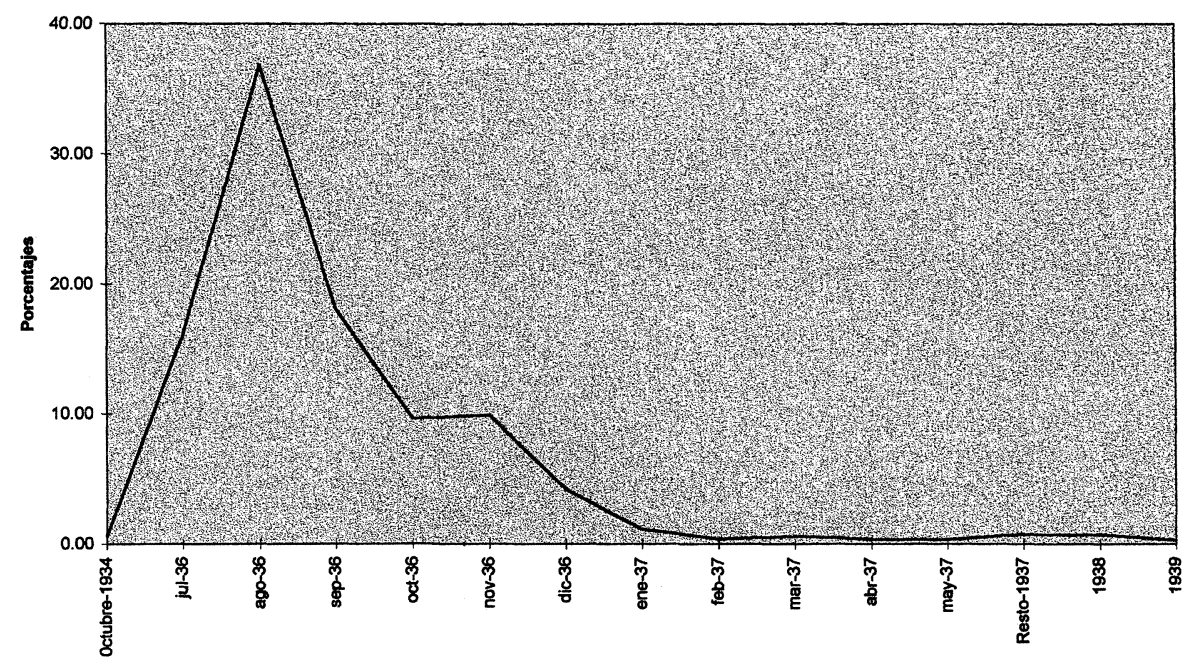

PERSECUCIÓN RELIGIOSA EN ESPAÑA. CRONOLOGÍA PORCENTAJES

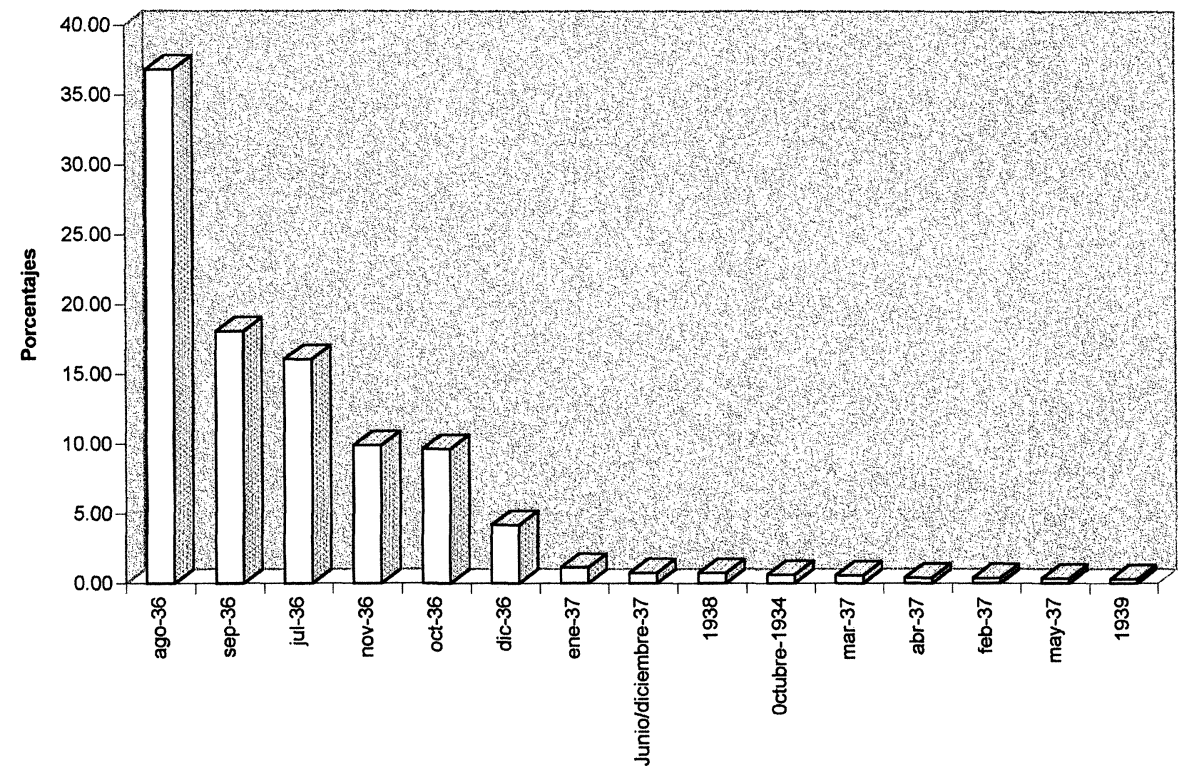

Actas del I Congreso de Historia de la Iglesia y el Mundo Hispánico Hispania Sacra 53 (2001) 
PERSECUCIÓN RELIGIOSA EN ESPAÑA. CRONOLOGÍA PORCENTAJES

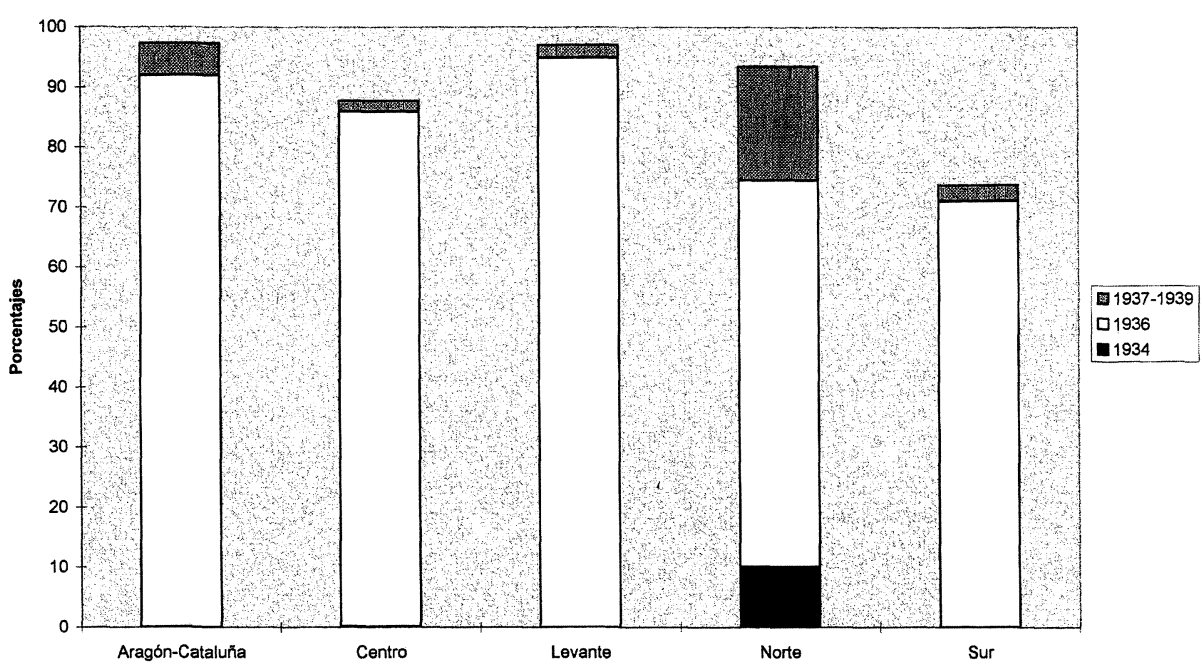

